The authors describe and evaluate an approach to engaging students in exploring social identities, understanding inequality, and identifying avenues for individual and collective action for greater social justice.

\title{
Intergroup Dialogue: A Critical- Dialogic Approach to Learning About Difference, Inequality, and Social Justice
}

\author{
Biren (Ratnesh) A. Nagda, Patricia Gurin
}

Intergroup dialogue (IGD) is an educational endeavor that brings together students from two or more social identity groups to build relationships across cultural and power differences, to raise consciousness of inequalities, to explore the similarities and differences in experiences across identity groups, and to strengthen individual and collective capacities to promote social justice. IGDs, comprised of about twelve to sixteen students, meet weekly over a period of ten to fourteen weeks. Trained peer facilitators use an educational curriculum that integrates multiple dimensions of learning: content and process learning; intellectual and affective engagement; individual reflection and group dialogue; individual, intergroup, and institutional analyses; affinity-based and heterogeneous groupings; and individual and collective action. Readings, reflective writing, and a collaborative action project complement the in-class dialogues (see Zúñiga, Nagda, Chesler, and Cytron-Walker, 2007, for a detailed description).

Intergroup dialogue builds on the traditions of diversity and social justice education but offers an innovative alternative. Diversity education aims to promote feelings of unity, tolerance, and acceptance within the existing societal structure (Sleeter and Grant, 2003). Social justice education teaches 
students about group-based inequalities, aims to promote greater social structural equality, and prepares students for citizenship in culturally pluralistic societies. However, what is generally missing from these two approaches is an explicit focus on cross-group interactions in the classroom as a crucial nexus of learning. Intergroup dialogue addresses this missing focus on classroom interaction, stressing three components of a critical-dialogic approach:

- Critical analysis and understanding of difference and dominance

- Discursive engagement across differences

- Sustained and conjoint community building and conflict engagement

\section{Critical Analysis and Understanding of Difference and Dominance}

Critical analysis, in IGD, refers to understanding inequalities as contextualized in structural systems rather than just in individual differences (Miller, 1994; Nagda, 2006). Intergroup dialogue situates group differences and inequalities in the context of sociostructural and power relations, such as institutional racism or patriarchy. Critical consciousness cannot be imposed on the students, nor is it immediate; it is both developmental and cyclical in nature. In the early sessions, students reflect on multiple social group membershipsincluding identities of race, ethnicity, gender, class, sexual orientation, national origin, religion and spirituality, ability, and age. They dialogue about the identities that are important to them. They also reflect and discuss identities that they do not consider important and inquire why that is. Students reflect later on their socialization into identities and examine the influence of peers and family, cultural sources, and social institutions (Harro, 2000). Thus IGDs help students personalize the connection between identities and inequalities. Students continue their conscientization (Freire, 1970) through inquiry on the interconnections among educational, occupational, legal, and other institutions in structuring systems of unequal power and privilege.

IGD research shows strong evidence for students' increased critical consciousness. In two studies using pretest-posttest surveys, students report thinking more about their social group memberships (Nagda and Zúñiga, 2003) and thinking more complexly about larger societal and historical influences on their own and others' behaviors (Nagda, Gurin, and Lopez, 2003). Particularly noteworthy are two studies focusing on students' causal understanding of inequalities. For example, one study of first-year undergraduates comparing IGD participants to a matched comparison group of nonparticipants (matched on race, gender, residency in or out of state, and residence hall) found that participants thought more structurally about racial and ethnic inequalities than their counterparts did (Lopez, Gurin, and Nagda, 1998) at the end of the course. Participants more strongly agreed with such statements as "In the United States, there are still great differences between social levels-what one can achieve in life depends mainly on one's 
family background" and less strongly agreed with such statements as "A person's racial background in this society does not interfere with achieving everything he or she wants to achieve." The study also checked for selfselection into the course but did not find differences at entry into college.

\section{Discursive Engagement Across Differences}

Discursive engagement refers to the nature of communicative interactions students have with each other. Table 5.1 differentiates three communication modes-debate, discussion, and dialogue. Debates in the classroom are used for students to use evidence-based thinking on issues, develop verbal presentation skills, and strengthen abilities to influence others by defending one's position and countering differing positions (Keller, Whitaker, and Burke, 2001). Discussion may be used for deliberative decision making (Parker, 2003) or be more conversational to foster self-awareness and selfcritique and may consist of affiliating with others through an appreciation of diversity of perspectives (Brookfield and Preskill, 2005). The concepts of debate and discussion are generally understood, but dialogue has a particular meaning in this context that requires further explanation.

Dialogue aims to foster empathic connection, understanding through inquiry, and mutual respect (Nagda and others, 1999). Dialogue practitioners agree that it is an open-ended process that allows all participants to gain new or deeper ways of thinking, to build relationships with others, and to work effectively on collaborative projects. Linda Teurfs, in an interview with Weiler (1994), identified four building blocks crucial to dialogue: suspending judgment, deep listening, identifying assumptions, and reflection and inquiry. Engagement encompasses the verbal and nonverbal, the intellectual and affective, and the individual and group levels. Careful facilitation in dialogue includes all students, helps them build connections among perspectives by identifying differences and similarities, and presses for both personalization and deeper understanding of assumptions that underlie perspectives (Bohm, 1990; Flick, 1998; Yankelovich, 1999).

IGD may at times use all three modes, although dialogue predominates over debate and discussion. Given the emphasis on critical analysis of inequality in IGD, dialogue serves as a liberatory communicative process that is both pedagogical and political, building relationships among people who are differentially affected by social stratification and asymmetric power relations. Interrelated learning activities, such as social identity affinity groups (Zúñiga and Nagda, 1993) and fishbowls (Schoem, Zúñiga, and Nagda, 1993), help explain how differential privilege and power affect individuals in the separate groups and across the groups in dialogue. Instead of differences being divisive, explicit acknowledgment and dialogue about the differentials can facilitate more connective relationships (Collins, 1996).

Two studies speak directly to the purposefulness of dialogic engagement processes. First, Yeakley's qualitative study of change processes in 


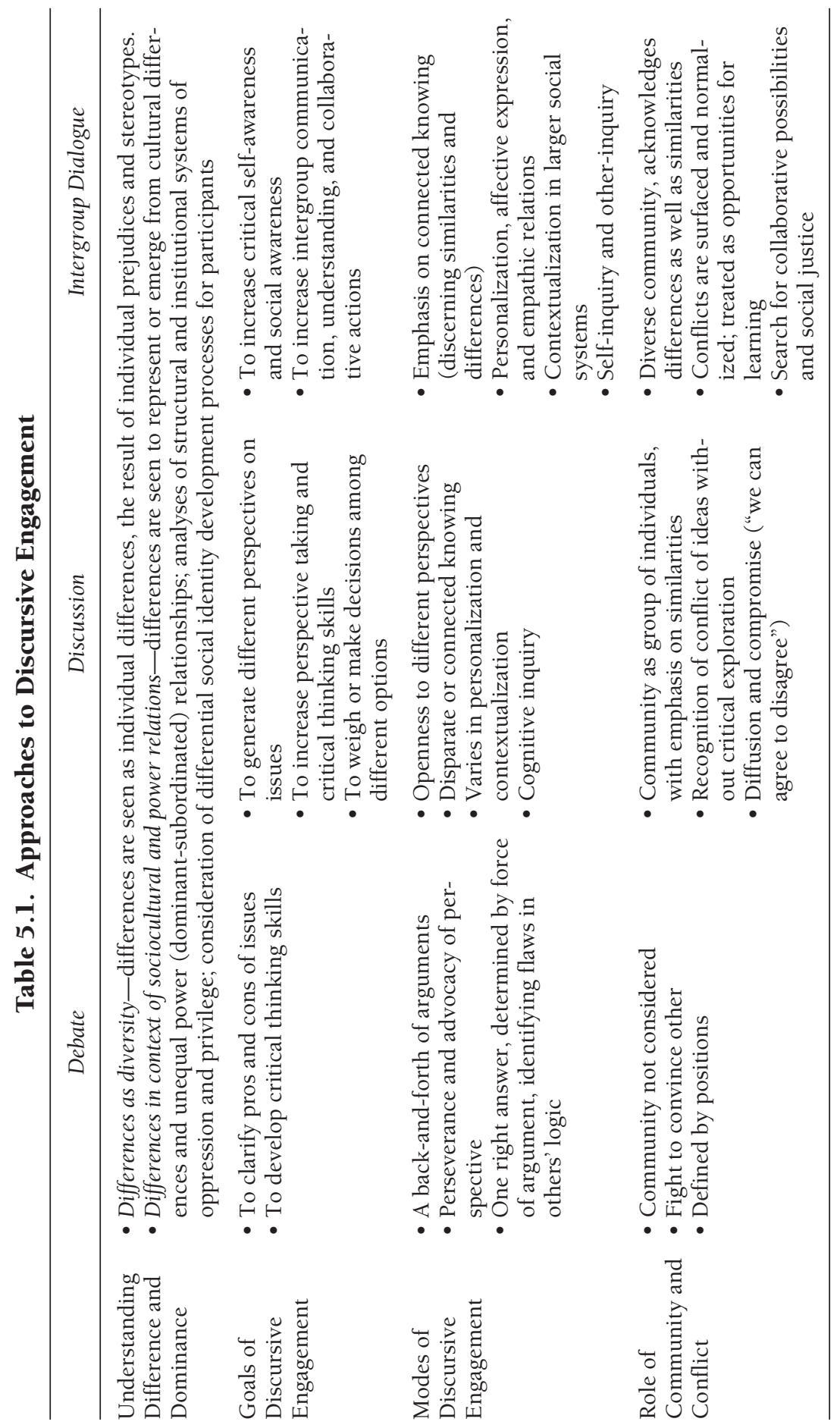


intergroup contact (1998) found that sharing and hearing personal experiences in a supportive climate differentiated positive and negative intergroup contact experiences. When personal experiences revolved around similarities, participants developed cross-group friendships. However, if personal experiences brought up differences, participants gained an understanding of multiple perspectives. If the differences were further understood vis-à-vis social identities, participants gained greater intergroup understanding. Second, Nagda's quantitative study (2006) asked students to indicate the extent to which a set of communication processes had contributed to their learning at the end of intergroup dialogues. Factor analysis revealed four distinct processes. Two processes reflect dialogic engagement: appreciating difference (learning about others and hearing about different points of view) and engaging self (complementing learning about others with sharing of one's own perspectives and rethinking them). Two others reflect critical engagement: critical self-reflection (examination of one's ideas, experiences, and perspectives in the context of inequality, privilege, and oppression) and alliance building (relating to and thinking about collaborating with others in taking actions toward social justice). Together these studies show that the deeper the personalization and the greater the contextualization of issues in intergroup dialogue, the wider the range of learning for students, from intergroup friendships to intergroup understanding and collaborative actions.

\section{Sustained and Conjoint Community Building and Conflict Engagement}

Some critics may argue that IGD is "just talk" and that talking about identity, difference, and inequality only escalates conflict and separation among groups. Our research and practice say otherwise. The communicative possibility embedded in intergroup dialogue provides an understanding of societal divisions and inequalities but also demonstrates that we are neither confined nor destined to remain static in social estrangement. It does mean, though, that we have to actively and earnestly reach across our differences and, as Collins (1996) says, "work toward replacing judgments by category with new ways of thinking and acting. Refusing to do so stifles effective coalition and social change" (p. 223). It also means that we must grapple honestly with the place and role of conflict and community as we engage deeply with and across our differences.

In IGD, community is built across differences and through the deep exploration of differences and conflicts. In contrast to debate, in which community is not of concern, and to discussion, where community is built around superordinate groups (such as "all students"), community in intergroup dialogue honors separate social group identities and encourages an appreciation of a common group identity constructed around alliance building and the work of social justice. Whereas conflicts in debates are around positions and in discussion around ideas, conflicts in intergroup dialogues 
are connected to identities, social structures, and relationships. Conflict engagement thus plays an important role in deepening the dialogic relating, expanding students' understanding of the issues that influence conflicts, and building students' capacity to work through disagreements and conflicts in productive ways. When conflicts emerge in the group, they are not taken as a sign of failed dialogue; rather, they are opportunities for deeper learning. Similarly, working through conflicts is not automatically assumed to lead to a breach in the relationship; in fact, it is exactly because of working through conflicts that a deeper sense of community is developed.

How do we sustain engagement with differences in ways that connect us and not estrange us further? Community building and conflict engagement are processes that unfold and develop over the duration of the dialogues. We take an intentional approach to preparing and building the container for dialogue, engaging conflict (that is, surfacing and responding to conflict), and applying the learning. In the first one or two sessions in IGD, explicit attention is given to forming engagement guidelines and building a learning community. Facilitators emphasize that talking about the issues of difference, identity, and inequality is not easy and that disagreements and conflicts are part and parcel of good dialogues.

As the intergroup dialogues progress, we use a variety of approaches to surface and respond to conflicts. In the case of overt disagreements and conflicts, facilitators usually name the conflicts instead of avoiding them. They emphasize dialogic engagement by modeling and facilitating active listening, perspective taking, and asking questions so that the different perspectives are clearly understood. With more subtle or covert conflicts, facilitators pay particular attention to the dynamics of privilege and oppression that may emerge in the group, such as dominating talking time by a few members, unequal emotional sharing, privileging objective information over emotions, denying other people's experiences of discrimination or marginalization, and one-way questioning by dominant group members of subordinated group members (Narayan, 1988). When this happens, facilitators may "freeze frame" and ask students to reflect on and voice how they were feeling and what they were noticing in that particular moment. To continue unpacking the disagreements and conflicts in any instance, facilitators guide the group in mapping the emergent perspectives and probing who, from which identities, is saying what and the consequent impact on dialogue participants. They further contextualize the emerging differences and similarities in the dynamics of dominance and explore ways to bridge across the differences. Another reflective structure that facilitators use is the "dialogue about the dialogue" to explore students' experiences of the IGD to date, both positive and negative, and to think of ways to deepen the dialogue (Zúñiga, Nagda, Chesler, and Cytron-Walker, 2007).

Just as community building prepares for deeper conflict engagement, conflict engagement has consequences for strengthening the community. 
Opportunities for students to jointly apply their learning through collaborative projects are an important component of IGDs. For the Intergroup Collaboration Project, teams of three or four students work together on an action project supporting diversity and justice on the campus or in the community-brainstorming ideas, selecting an action, and planning, implementing, and debriefing their learning. Students report several lessons from these intergroup collaborations: a deeper understanding of inequality; an acute awareness of how issues of dominance, privilege, and oppression get enacted in their own teams; and a heightened confidence in using their learning to educate and inform others, challenge oppressive remarks and actions, and build alliances for social justice.

The practice and research of intergroup dialogue also reveal that community building and conflict engagement are useful for purposeful actions and commitments outside the group. Gurin, Peng, Lopez, and Nagda (1999), in their study comparing first-year students in an intergroup relations course to a matched comparison group of nonparticipants, found that students of color in the course perceived less divisiveness on campus than nonparticipants; they less strongly agreed that thinking about groups was largely divisive or that the university's emphasis on diversity meant that they could not talk honestly about racial, ethnic, and gender issues. There was no difference for white students and nonparticipants. In terms of commonality, they found that the course had differential effects across race. The course had a main effect for white students' feelings of commonality of interests and values with students of color. For students of color, commonality in values with white students increased for those who were more strongly identified racially or ethnically. However, the course had a main positive effect for the quality of interactions that students of color had with white students. The course also had a positive impact on all students' positive beliefs about conflict. Gurin, Nagda, and Lopez (2004) surveyed the same students four years later and found that course participants were more interested in politics, participated more in campus politics, and more highly anticipated helping their groups or community and promoting racial and ethnic understanding than the matched control students did.

A series of studies using pretest-posttest surveys of participants have further investigated the influence of classroom teaching and learning methods on community and conflict outcomes. First, Nagda and Zúñiga (2003) found that students' value for the dialogic engagement was positively related to their affirmative views about conflict (for example, "I believe that conflicts and disagreements in the classroom enrich the learning process" and "I think that conflicts between social identity groups can help clarify misunderstandings that each group has about the other"). Positive influences were also seen for one measure of community-bridging differences (for example, "I want to bridge differences between different social identity groups"). Second, Gurin, Nagda, and Lopez (2004) showed that the 
informational content and intergroup interactions in intergroup dialogue help build a learning community that allows for learning about one's own group and other groups, reflecting more on one's own group, and bridging differences between groups. The motivation to bridge differences was directly related to greater confidence in reducing one's own prejudiced thoughts and behaviors and promoting diversity with and among others. Zúñiga's research (2004) found that students defined actions similar to what they were doing in the dialogues_-taking risks, talking with others, and educating themselves and others. One could make a case for intergroup dialogues becoming an in vivo learning environment where students experiment with and refine their motivation and skills for action outside the dialogues. In a later study, Nagda (2006) found that the four communication processes mentioned earlier-appreciating difference, engaging self, critical self-reflection, and alliance building-have a concerted impact on bridging differences. Most interestingly, the communication process of alliance building —working through differences and conflicts, challenging biases and assumptions, and developing commitments to social justicedeepens the desire to bridge differences.

\section{Advancing the Scholarship of Teaching and Learning of Intergroup Dialogues}

To build on the strengths of the existing research and address its limitations, the scholarship of intergroup dialogues is now extended in a multiuniversity research study. Nine universities (seven public, two private) are collaborating on this project: Arizona State University; Occidental College; Syracuse University; University of California, San Diego; University of Maryland, College Park; University of Massachusetts at Amherst; University of Michigan, Ann Arbor; University of Texas at Austin; and University of Washington, Seattle. The research project is theoretically driven; it involves both race and gender dialogues in which we aim to have an equal number of white men, white women, men of color, and women of color participate; and it uses random assignment of interested students to an intergroup dialogue or a wait-list control group. We elaborate on the main components of the project and how they address the limitations of the existing research as follows.

Theoretically driven study. Unlike previous studies, the multiuniversity project specifically tests a theory of intergroup dialogue that links the IGD intervention to outcomes via individual psychological and situational communication processes. The project also extends the range of outcomes considered-intergroup understanding of inequalities, intergroup communication, and intergroup collaboration-and the breadth of processes examined-individual, situational, and group-level.

Addressing internal validity. Because of the lack of studies using matched comparison groups of students, attribution of outcomes solely to intergroup dialogue are difficult to assess. The multiuniversity study uses randomized 
assignment of students to the experimental group (the intergroup dialogue) and to a wait-list control group from applicants interested in participating in either a race or a gender dialogue. The randomized assignment, combined with the theoretical model, will help clarify not only if intergroup dialogue are effective or not but also what mechanisms increase or reduce effectiveness.

Addressing external validity. Because previous studies have been conducted exclusively at single institutions, the findings cannot necessarily be generalized. The multiuniversity project addresses the limitation of generalizability through its collaboration of ten colleges and universities across the United States.

Generalization across participants. The current study balances participants by both race and gender: ideally, there are four women of color, four white women, four men of color, and four white men in each race and gender dialogue. The study will thus for the first time enable us to look at similarities and differences across these demographic groups.

Mixed-methods research. The multiuniversity study uses both quantitative and qualitative methods. On the quantitative side, we use a pretestposttest survey as well as a follow-up survey one year after participation. Qualitatively, in-class reflection papers will capture the emotional processes evoked by experiential activities, final papers will be analyzed for both processes (such as engaging self and critical self-reflection) and outcomes (such as empathy and structural understanding of inequality), and individual interviews and videotaping of select sessions will help elucidate descriptive information about learning outcomes as well as individual and group processes.

\section{Conclusion}

The scholarship of teaching and learning of intergroup dialogues shows that involving students in intellectual and affective interactions with fellow classmates-voicing their convictions and trepidations, listening to each other's desires for connection and fears of betrayal, inquiring into how each of their experiences is influenced by the larger social realities, and knowing deeply that one's own sense of humanity is interconnected to how we are with each other-can contribute to democratic living just not politically but personally as well. The multiuniversity intergroup dialogue research project will deepen and expand our understanding of the unique critical-dialogical engagement as one avenue to empower students to know and to learn, to care and to act, and to be and to interact in more socially just ways in the world.

\section{References}

Bohm, D. On Dialogue. Ojai, Calif.: David Bohm Seminars, 1990.

Brookfield, S., and Preskill, S. Discussion as a Way of Teaching: Tools and Techniques for Democratic Classrooms. San Francisco: Jossey-Bass, 2005. 
Collins, P. H. "Toward a New Vision: Race, Class, and Gender as Categories of Analysis and Connection." In K. Rosenblum and T. Travis (eds.), The Meaning of Difference: American Constructions of Race, Sex and Gender, Social Class, and Sexual Orientation. New York: McGraw-Hill, 1996.

Flick, D. From Debate to Dialogue: Using the Understanding Process to Transform Our Conversations. Boulder, Colo.: Orchid, 1998.

Freire, P. Pedagogy of the Oppressed. New York: Continuum, 1970.

Gurin, P., Nagda, B. A., and Lopez, G. E. "The Benefits of Diversity in Education for Democratic Citizenship." Journal of Social Issues, 2004, 60(1), 17-34.

Gurin, P., Peng, T., Lopez, G. E., and Nagda, B. A. "Context, Identity, and Intergroup Relations." In D. Prentice and D. Miller (eds.), Cultural Divides: Understanding and Overcoming Group Conflict. New York: Russell Sage Foundation, 1999.

Harro, B. "The Cycle of Socialization." In M. Adams, L. A. Bell, and P. Griffin (eds.), Readings for Diversity and Social Justice: An Anthology on Racism, Anti-Semitism, Sexism, Heterosexism, Ableism, and Classism. New York: Routledge, 2000.

Keller, T. E., Whittaker, J. K., and Burke, T. K. "Student Debates in Policy Courses: Promoting Policy Practice Skills and Knowledge Through Active Learning." Journal of Social Work Education, 2001, 37(2), 343-355.

Lopez, G. E., Gurin, P., and Nagda, B. A. "Education and Understanding Structural Causes for Group Inequalities." Journal of Political Psychology, 1998, 19(2), 305-329.

Miller, F. "Why We Chose to Address Oppression." In E. Y. Cross, J. H. Katz, F. A. Miller, and E. W. Seashore (eds.), The Promise of Diversity: Over 40 Voices Discuss Strategies for Eliminating Discrimination in Organizations. Burr Ridge, Ill.: Irwin, 1994.

Nagda, B. A. "Breaking Barriers, Crossing Boundaries, Building Bridges: Communication Processes in Intergroup Dialogues." Journal of Social Issues, 2006, 62(3), 553-576.

Nagda, B. A., Gurin, P., and Lopez, G. E. "Transformative Pedagogy for Democracy and Social Justice." Race, Ethnicity and Education, 2003, 6(2), 165-191.

Nagda, B. A., and others. "Intergroup Dialogues: An Innovative Approach to Teaching About Diversity and Justice in Social Work Programs." Journal of Social Work Education, 1999, 35(3), 433-449.

Nagda, B. A., and Zúñiga, X. "Fostering Meaningful Racial Engagement Through Intergroup Dialogues." Group Processes and Intergroup Relations, 2003, 6(1), 111-128.

Narayan, U. "Working Together Across Difference: Some Considerations on Emotions and Political Practice." Hypatia, 1988, 3(2), 31-47.

Parker, W. Teaching Democracy: Unity and Diversity in Public Life. New York: Teachers College Press, 2003.

Schoem, D., Zúñiga, X., and Nagda, B. A. "Exploring One's Background: The Fishbowl Exercise." In D. Schoem, L. Frankel, X. Zúñiga, and E. Lewis (eds.), Multicultural Teaching in the University. Westport, Conn.: Praeger, 1993.

Sleeter, C. E., and Grant, C. Making Choices for Multicultural Education: Five Approaches to Race, Class, and Gender. Hoboken, N.J.: Wiley, 2003.

Weiler, J. "Finding a Shared Meaning: Reflections on Dialogue. An Interview with Linda Teurfs." Seeds, 1994, 11(1), 5-10.

Yankelovich, D. The Magic of Dialogue: Transforming Conflict into Cooperation. New York: Simon \& Schuster, 1999.

Yeakley, A. "The Nature of Prejudice Change: Positive and Negative Change Processes Arising from Intergroup Contact Experiences." Unpublished doctoral dissertation, University of Michigan, 1998.

Zúniga, X. "The Ripple Effects of Talking About Race and Gender: Moving from Dialogue to Action." Paper presented at the American Educational Research Association (AERA) National Conference, San Diego, Calif., April 2004.

Zúñiga, X., and Nagda, B. A. "Identity Group Exercise." In D. Schoem, L. Frankel, X. Zúñiga, and E. Lewis (eds.), Multicultural Teaching in the University. Westport, Conn.: Praeger, 1993. 
Zúñiga, X., Nagda, B. A., Chesler, M., and Cytron-Walker, A. Intergroup Dialogues in Higher Education: Meaningful Learning About Social Justice. ASHE Higher Education Report Series, no. 32, iss. 4. Hoboken, NJ: Wiley, 2007.

BIREN (RATNESH) A. NAGDA is associate professor of social work and director of the Intergroup Dialogue, Education and Action (IDEA) Center at the University of Washington.

PATRICIA GURIN is the Nancy Cantor Distinguished Professor, Emerita, of psychology and women's studies, and the director of research for the Program on Intergroup Relations at the University of Michigan. 